\title{
Research on the Willingness to Use Mobile Payment Platform Based on Trust Theory
}

\author{
Fang Wang, Jing You*, Dekun Rao, Xiaomin He \\ Center for service science and engineering, School of Management, Wuhan University of Science and Technology \\ Wuhan, China, 430083 \\ wangfang79@wust.edu.cn,yau720@qq.com,478228445@qq.com, 281735641@qq.com
}

\begin{abstract}
Mobile payment platforms have developed rapidly due to their convenience and flexibility, low transaction and time costs. Based on trust theory, this paper constructs the structural equation model and the assumption of the willingness to use mobile payment platform based on the detailed analysis of personal factors, perceived benefits and perceived risks. The constructed models and assumptions were validated by combining AMOS17.0 with SPSS13.0. The research results further show that personal attitudes, knowledge factors, perceived ease of use, cognitive trust, perceived usefulness are positively related to the trust of the payment platform, economic risks and privacy risks are negatively correlated with trust, and the dimensions of perceived emotional trust, perceived credit and cognitive trust have no significant effect on outcome.
\end{abstract}

Keywords-Mobile payment platform; Trust; Influential factors; Usage intention

\section{INTRODUCTION}

As of June 2017, Chinese netizens reached 751 million, accounting for one fifth of the total global Internet users [1]. Meanwhile, according to the China Internet Network Information Center (CNNIC) released the 39th "China Internet Development Statistics Report" shows, the number of mobile payment users in China increased rapidly in 2016, reaching 469 million, annual growth rate of $31.2 \%$. The proportion of online payment used by mobile phone users increased from 57.7 to $67.5 \%$ [2]. The above data prove that with the rapid development of network economy and mobile websites, the mobile payment platform has become an important means of consumer payment.

The development of mobile payment platform benefits from the vigorous promotion of mobile devices, the rapid development of the Internet economy, and the transformation of wireless information and communication methods. With the current development situation and development trend, mobile means of payment is likely to be due to its incomparable advantages to replace the existing traditional means of payment. It had been widely adopted and used in the field of consumer payments, shopping and payment [3]. The significant advantage of mobile payments is that it has a strong mobility, this payment method primarily through mobile phone as the representative of the mobile device, wireless communication of information exchange, its existence and rise of electronic money is inseparable. These are the characteristics of mobile payments.

The behavior of consumers uses the payment platform is based on their willingness to use. From the technology acceptance model and diffusion theory of innovation, we can see that the usefulness and usability of products, hidden uncertainty in the transaction process, mutual cooperation, and social pressure on whether individuals take action are the influencing factors for users to use mobile payment platforms. Lan Junyao believes that the role and impact of others, innovation of oneself, the expected value of these three factors play a significant role for young users to use the mobile payment platform, the most obvious of which is the role and influence of others [4]. Feng Xin [5] and Wang Xin [6] think that there are still major problems in security, policies and regulations, credit system and consumption habits, etc. Zhang Shengdao [7] and Liu Junjian [8] pointed out that the lack of market supervision and relevant rules and regulations as well as market penetration is not enough to restrict the development of mobile payment platform.

Under the current circumstances, how to grasp the changes in consumers' hearts and increase consumers' trust in payment platforms is one of the key factors for each payment platform to win in the competition.

\section{RELATED LITERATURE REVIEW}

Fishbein and Ajzen define behavioral intentions as the possibility of an individual's action. Harrison defines behavioral intentions as the degree to which an individual produces an automatic process of behavior. Zeithmal suggests that willingness plays a key role in consumer psychology and attitudes. According to Zeithmal et al.'s research on purchase intention, consumers' purchase intention can be divided into positive intention and negative intention [9]. Generally, when an individual support for a specific product or service, his behavior intention will be positive. When an individual has an objection attitude, the likelihood of his action is greatly reduced [10]. Therefore, the consumer's willingness to use is the probability and probability of using the mobile payment method to complete the payment after completing the selection of related products or services. When discussing the willingness to use a product, it mainly discusses four dimensions: personal factor, perceived risk, perceived value, and product trust. 
paper proposes the assumptions: personal factors and each dimension of trust have a positive correlation.

2) Relationship between perceived benefits and each dimension of trust.

In this paper, perceived benefits are divided into perceived usefulness, perceived ease of use and perceived reputation. Perceived usefulness mainly refers to the increasing consumer profits, reduce consumer costs, it is emphasized that the result of the completion of the payment, such as access to a good payment experience, save the transaction time, get the benefits, the scope of the business involved is very wide. Perceived ease of use mainly refers to the consumer in the process of operating the mobile payment is very easy, it emphasizes the convenience of payment, such as access to the operation of the page fast, quick navigation, payment page is clear and easy to understand, payment is simple and easy and so on. Perceived credit mainly refers to the consumer understands the credibility of the platform through the Internet search, social evaluation, public opinion and other forms, the better the credibility of the platform, the easier it is for consumers to have a sense of trust. Therefore, this paper proposes the assumptions: perceived benefits and various dimensions of trust have a positive correlation.

3) The relationship between perceived risks and each dimension of trust.

This article divides perceived risks into economic risks and privacy risks. The perceived economic risks of consumers on mobile payment platforms mainly refer to the loss or theft of mobile phones, loss of bank card passwords, and other property losses. The specific performance of consumer personal basic information and bank card information will be stolen due to the negligence of network technology. Therefore, this paper proposes the assumptions: perceived risk and each dimension of trust have a negative correlation.

4) The relationship between trust and consumer's usage intention

When consumers generate trust, that is, establish cognitive trust and emotional trust, they will have a psychological dependence on the mobile payment platform, so their willingness to use will be stronger. Consumers' willingness to use is brought about by the trust in the payment platform, including cognitive trust and emotional trust on the platform. Therefore, this paper proposes the assumptions: trust and consumer's usage intention have a positive correlation.

\section{B. Modeling}

Based on the above literature analysis and assumptions, the initial model of the study was constructed. Trust affects consumer's willingness to use, and personal factors, perceived benefits, and perceived risks are factors that influence trust.
1) The relationship between personal factors and each dimension of trust

In this article, individual factors are divided into personal attitude and personal knowledge. The personal attitude of consumers is an important factor that affects consumers' willingness to use. The more positive the consumer's attitude, the more likely he is to have a sense of trust and thus a willingness to use. Personal knowledge is the level of understanding and mastery of the relevant knowledge about consumers' payment methods, instructions, advantages and disadvantages with mobile payment platform. Therefore, this 


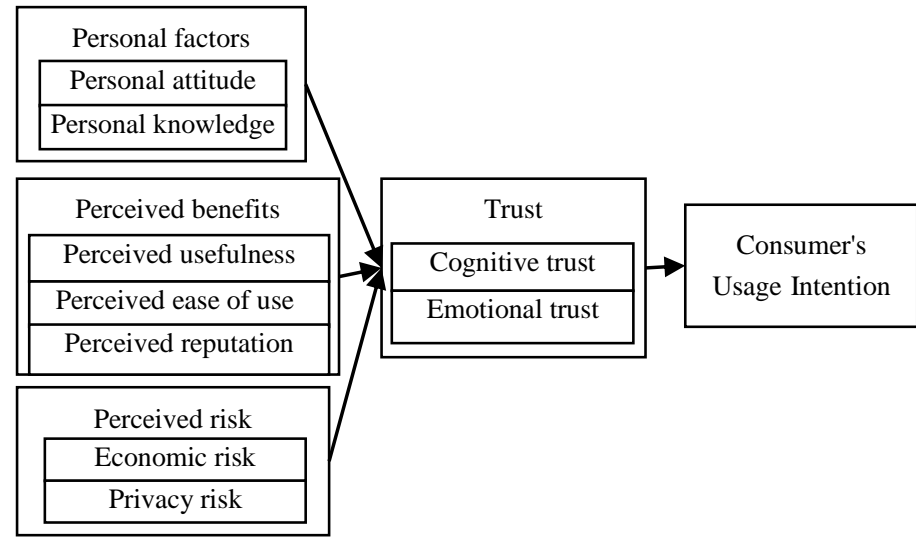

Fig. 1. Study the initial model.

\section{DATA ANALYSIS AND EMPIRICAL RESEARCH}

\section{A. The basic description of the sample}

In order to collect relevant data, a questionnaire survey scale was designed, as showed in Table 1. According to the scale design specific questionnaire, see the appendix. The three-day online survey was powered by www.wjx.cn and merchant-assisted offline investigations.
The survey collected a total of 315 valid questionnaires, including 180 males, accounting for $57.1 \%$, 135 females, accounting for $42.9 \%$, the proportion of men and women more balanced. In terms of age distribution, $41.9 \%$ are under 25 , $40.6 \%$ are from 26 to 35, and 36-45 and over 45 years old are relatively small. This is because less than 35 years old is the main body of mobile payment and online consumption. Taking into account the purpose of the research population, the results are basically in line with the normal distribution, to meet the needs of this study. The use of mobile phone to pay for this variable, the use of people reached $96.8 \%$, in line with the survey of social characteristics, indicating the reliability of the questionnaire recovery.

\section{B. Description of statistical analyses of variables}

Table 1 shows descriptive statistics for each variable in the structural equation model in this study. The sample size of the table is 315 . The minimum value of all variables is 1 and the maximum value is 5 . The mean range of each variable is 2.83 3.3 .52 , and the standard deviation range is $0.833-1.086$. The data distribution is more in line with the normal distribution.

TABLE I. THE DESCRIPTION OF EACH VARIABLE STATISTICAL ANALYSIS RESULTS

\begin{tabular}{|c|c|c|c|}
\hline variables & Measurement of variables & Mean & Standard deviation \\
\hline \multirow{3}{*}{ Personal attitude } & Q1. Mobile payment method has a positive development. & 3.35 & 0.896 \\
\hline & Q2. I have a supportive attitude towards mobile payment platform. & 3.31 & 0.876 \\
\hline & Q3. Mobile payment method can be vigorously promoted. & 2.89 & 1.086 \\
\hline \multirow{2}{*}{$\begin{array}{c}\text { Personal } \\
\text { knowledge }\end{array}$} & Q4. Mobile payment platform to understand more comprehensive. & 2.94 & 1.081 \\
\hline & Q5. The operation, advantages and disadvantages of mobile payment methods are relatively clear. & 2.98 & 1.008 \\
\hline \multirow{3}{*}{$\begin{array}{l}\text { Perceived } \\
\text { usefulness }\end{array}$} & Q6. The scope and area of use of mobile payments are broader, such as movie tickets, payment. & 3.30 & 0.942 \\
\hline & Q7. Mobile payment platform has a shorter payment time. & 3.26 & 0.942 \\
\hline & Q8. Mobile payment methods are more convenient. & 3.39 & 0.936 \\
\hline \multirow{4}{*}{$\begin{array}{c}\text { Perceived ease of } \\
\text { use }\end{array}$} & Q9. The operation steps of the mobile payment platform are very simple. & 3.47 & 0.875 \\
\hline & Q10. The mobile payment platform has a fast user interface. & 3.34 & 0.922 \\
\hline & Q11. Mobile payment interface is clear and easy to understand & 3.44 & 0.833 \\
\hline & Q12. Learning the process of mobile payments is easy. & 3.25 & 0.946 \\
\hline \multirow{2}{*}{$\begin{array}{l}\text { Perceived } \\
\text { reputation }\end{array}$} & Q13. Most mobile payment platforms have good reputation. & 2.97 & 1.043 \\
\hline & Q14. Most mobile payment platforms are able to comply with business ethics. & 2.88 & 1.026 \\
\hline \multirow{3}{*}{ Economic risk } & Q15. The use of mobile payment, bank card password easily stolen. & 3.41 & 0.860 \\
\hline & Q16. With mobile payments, loss of mobile phones can easily result in greater property damage. & 3.28 & 0.957 \\
\hline & Q17. The leakage of mobile payment passwords is not easy to report and cause property damage. & 3.29 & 0.914 \\
\hline \multirow{3}{*}{ Privacy risk } & Q18. Personal information is easily revealed during the use of mobile payment platforms. & 3.34 & 0.975 \\
\hline & Q19. Transaction information is easily tampered with in the process of using mobile payments. & 3.35 & 0.895 \\
\hline & Q20. Using mobile payment platforms makes it easier to receive spam messages. & 3.52 & 0.998 \\
\hline \multirow{3}{*}{ Cognitive trust } & Q21. The mobile payment platform's commitment in all aspects is credible. & 2.94 & 1.057 \\
\hline & Q22. The mobile payment platform is reliable in all aspects. & 2.88 & 1.025 \\
\hline & Q23. The mobile payment platform has a sense of responsibility. & 2.97 & 1.014 \\
\hline \multirow{2}{*}{ Emotional trust } & Q24. Mobile payment platforms do their best to meet the needs of users. & 2.83 & 1.066 \\
\hline & Q25. Mobile payment platforms care about the benifits of users. & 2.93 & 1.010 \\
\hline \multirow{2}{*}{ Usage Intention } & Q26. Very willing to try mobile payment methods. & 3.38 & 0.945 \\
\hline & Q27. Will use the mobile payment platform in the future & 3.38 & 0.897 \\
\hline
\end{tabular}

\section{Reliability Analysis}

Reliability test is used to measure the same concept of multiple indicators of consistency, to determine whether the data is reliable, reflecting the quality of the data. According to the study, a more reliable questionnaire in the total scale of the reliability coefficient should be greater than $0.8,0.7-0.8$ for the general; subscale reliability coefficient greater than $0.7,0.6-0.7$ for the general. We used SPSS 13.0 to analyze the data and found the reliability of each variable.

According to Table 2, we find that the total variable coefficient of this model is 0.869 , within the range of reference value $\alpha>0.8$, the reliability of the questionnaire is still very high. The coefficients of other variables except emotional trust are 
all greater than 0.7 , indicating the reliability of sub-variable table is still very good. Emotional trust coefficient of 0.69 ,

between $0.60-0.70$ and very close to 0.70 , it is still acceptable.

TABLE II. THE RELIABILITY ANALYSIS RESULTS OF THE QUESTIONNAIRE

\begin{tabular}{|c|c|c|c|}
\hline & \multicolumn{3}{|c|}{ Reliability statistics } \\
\hline Variable Description & Number of questions & Cronbach Alpha & Reference \\
\hline Total variables & 27 & 0.869 & referencevalue $\alpha>0.8$ \\
\hline Personal attitude & 3 & 0.730 & \multirow{10}{*}{ reference value $\alpha>0.7$} \\
\hline Personal knowledge & 2 & 0.772 & \\
\hline Perceived usefulness & 3 & 0.756 & \\
\hline Perceived ease of use & 4 & 0.744 & \\
\hline Perceived reputation & 2 & 0.712 & \\
\hline Economic risk & 3 & 0.782 & \\
\hline Privacy risk & 3 & 0.780 & \\
\hline Cognitive trust & 3 & 0.702 & \\
\hline Emotional trust & 2 & $\underline{0.693}$ & \\
\hline Usage Intention & 2 & 0.719 & \\
\hline
\end{tabular}

TABLE III. TEST RESULTS OF NORMAL DISTRIBUTION OF SAMPLE DATA

\begin{tabular}{|c|c|c|c|}
\hline variables & Item & Skewness & kurtosis \\
\hline \multirow{3}{*}{ Personal attitude } & Q1 & 0.156 & 0.4274 \\
\hline & Q2 & 0.100 & -0.337 \\
\hline & Q3 & 0.096 & -0.722 \\
\hline \multirow[b]{2}{*}{ Personal knowledge } & $\mathrm{Q} 4$ & -0.023 & -0.665 \\
\hline & Q5 & -0.087 & -0.486 \\
\hline \multirow{3}{*}{ Perceived usefulness } & Q6 & 0.024 & -0.416 \\
\hline & Q7 & 0.126 & -0.477 \\
\hline & Q8 & -0.148 & -0.272 \\
\hline \multirow{4}{*}{ Perceived ease of use } & Q9 & -0.103 & -0.300 \\
\hline & Q10 & 0.003 & 0.613 \\
\hline & Q11 & 0.078 & -0.540 \\
\hline & Q12 & 0.115 & -0.329 \\
\hline \multirow{2}{*}{ Perceived reputation } & Q13 & 0.013 & -0.615 \\
\hline & Q14 & 0.059 & 0.485 \\
\hline \multirow{3}{*}{ Economic risk } & Q15 & 0.081 & 0.344 \\
\hline & Q16 & -0.440 & -0.407 \\
\hline & Q17 & -0.017 & -0.209 \\
\hline \multirow{3}{*}{ Privacy risk } & Q18 & -0.061 & -0.603 \\
\hline & Q19 & 0.031 & -0.200 \\
\hline & Q20 & -0.521 & -0.136 \\
\hline \multirow{3}{*}{ Cognitive trust } & Q21 & -0.032 & -0.611 \\
\hline & Q22 & 0.072 & -0.549 \\
\hline & Q23 & -0.004 & -0.567 \\
\hline \multirow[b]{2}{*}{ Emotional trust } & Q24 & 0.109 & 0.537 \\
\hline & Q25 & 0.010 & $-0 . .581$ \\
\hline \multirow{2}{*}{ Usage Intention } & Q26 & -0.052 & -0.583 \\
\hline & Q27 & -0.168 & -0.164 \\
\hline
\end{tabular}




\section{Normal distribution tests}

The kurtosis and skewness were utilized to test the normal distribution of the samples. For statistical analysis, the peak value was close to zero, and the collected data were reduced by three. The test results are given in Table 3.

It can display in Table 3 that in the statistical results, the absolute values of skewness of all the data are in the range of $0-1$ and the absolute value of kurtosis (plus 3 ) is in the range of $0-2$. Therefore, the data obtained from the questionnaire conform to the normal distribution.

\section{STRUCTURAL EQUATION MODEL TEST AND HYPOTHESIS EXPLANATION}

\section{A. Structural equation model buildings}

The whole model was constructed in AMOS7.0, personal attitude was measured by three observation indexes, Q1, Q2 and Q3, personal knowledge was measured by Q4 and Q5, and the perceived usefulness was measured by Q6, Q7 and Q8. Similarly, perceived usability was measured by Q9, Q10, Q11, $\mathrm{Q} 12$, perceived reputation by $\mathrm{Q} 13, \mathrm{Q} 14$, economic risk by Q15,Q16, Q17, privacy risk by Q18, Q19, Q20, cognitive trust by Q21, Q22, Q23, emotional trust by Q24, Q25 and usage intention by Q26, Q27.

1) Result of the structural equation model.

We input the model diagram into the software of AMOS17.0, and the measurement results are presented in figure 2 .

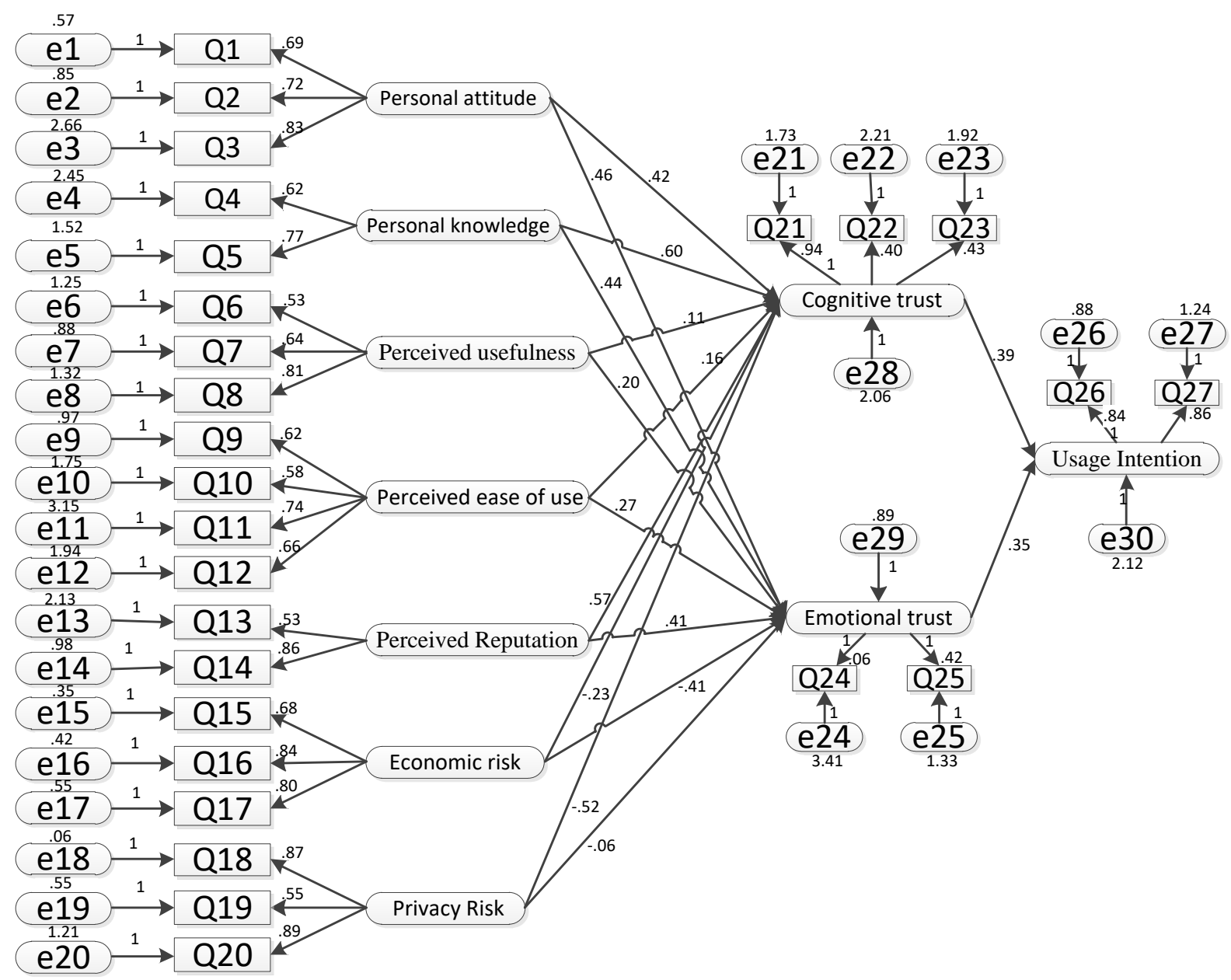

Fig. 2. Structural equation full model. 


\section{Table 4:}

The overall fitting indexes for the model are shown in

TABLE IV. FITTING INDEXES OF THE MODEL

\begin{tabular}{|c|c|c|}
\hline Fit Indexes & Display value & Reference value \\
\hline Chi square $\chi^{2}$ & 935.483 & $/$ \\
\hline Degree of freedom(df) & 408 & $<3$ \\
\hline$\chi^{2} / \mathrm{df}$ & 2.293 & $>0.80$ \\
\hline Goodness of fit index (GFI) & 0.852 & $>0.80$ \\
\hline Comparison fitting index(CFI) & 0.908 & $>0.90$ \\
\hline Tucker Lewis Index(TLI) & 0.903 & $<0.1$ \\
\hline Root mean square error of approximation (RMSEA) & 0.073 & \\
\hline
\end{tabular}

It can be seen from Table 4 that $\chi^{2} / \mathrm{df}$ is 2.293 , and the fitting result can be accepted within the range of reference value $<3$. GFI is $0.852>0.80$, CFI, TLI are greater than 0.90 , and RESEA $<0.1$, indicating that the fitting index of the variable measurement model is better, the fitting degree is relatively prominent, so the overall model fitting degree test.

\section{2) Analysis of the result.}

The $\mathrm{P}$ value was used to test the statistical significance of the path coefficients. According to the result, the $\mathrm{p}$ value of the correlation between perceived reputation and cognitive trust was 0.081 , and the value of the correlation between perceived ease of use and emotional trust was 0.073. All other tested $P$ values are much less than 0.05 , indicating that the original path assumptions are basically reasonable.
From Figure 2, it is known that: the direct impact on cognitive trust in descending order of personal knowledge, perceived reputation, personal attitude, perceived ease of use, and perceived usefulness; the direct impact on emotional trust in descending order of personal attitude, personal knowledge, perception reputation; the direct impact of cognitive trust and emotional trust on the usage intention is not much difference, both cannot be ignored.

From Table 5, it is known that: the direct impact on usage intention in descending order of economic risk, privacy risk and perceived reputation. Among them, the influence of economic risk and privacy risk on usage intention is negatively correlated. Therefore, we should pay special attention to these two factors and solve them.

TABLE V. INDIRECT EFFECTS BETWEEN VARIABLES

\begin{tabular}{|c|c|}
\hline Route & Indirect effects \\
\hline Personal attitude $\rightarrow$ Usage Intention & .250 \\
\hline Personal knowledge $\rightarrow$ Usage Intention & .305 \\
\hline Perceived usefulness $\rightarrow$ Usage Intention & .312 \\
\hline Perceived ease of use $\rightarrow$ Usage Intention & .213 \\
\hline Perceived reputation $\rightarrow$ Usage Intention & .354 \\
\hline Economic risk $\rightarrow$ Usage Intention & -.382 \\
\hline Privacy risk $\rightarrow$ Usage Intention & -.356 \\
\hline
\end{tabular}

\section{CONCLUSION}

Based on the theory of trust, this paper studies consumer's influence on cognitive trust and emotional trust of products through personal factors, perceived benefits, and perceived risks, so as to study the influence of consumers on the willingness to use mobile payment platforms. Through the data of scale design and questionnaire survey, the structural equation model was constructed to obtain the correlation between factors and intermediate variables and outcome variables. The main conclusions are as follows:

(1) Personal attitudes and personal knowledge are two of the personal factors that have a positive correlation with the psychological trust of consumers and thus affect consumers' willingness to use.

(2) Among factors that affect cognitive trust, personal knowledge has the highest impact on cognitive trust. Among factors that affect emotional trust, personal attitudes and personal knowledge have a high impact on emotional trust.

(3) Perceived risk is the most significant factor affecting the consumers' willingness to use. The indirect impact on the willingness to use is the economic risk, privacy risk and perceived credit in descending order. 


\section{REFERENCES}

[1] Economic View. The scale of Chinese netizens reaches 751 million[ED/OL].http://wemedia.ifeng.com/24846036/wemedia.shtml, 2017-08-04.

[2] Prospective industry research institute. Alipay over 450 million active users of mobile payment eras are irreversible? [ED/OL].
[ http://finance.jrj.com.cn/2017/07/26092222799201.shtml,2017-07-26.

[3] Xie Ping, Liu Haier. ICT, mobile payment and electronic money [J]. Financial research. 2013(10):1-14(In Chinese)

[4] Lan Junyao. Analysis of factors influencing the acceptance and use of mobile payments for young users [D]. Huazhong Normal University master's degree thesis, 2012.6-10. (In Chinese)

[5] Feng Xin. Problems and suggestions for the development of mobile payment in China [J]. Hebei finance, 2015 (11): 67-72. (In Chinese)

[6] Wang Xin. Current situation and trend analysis of mobile payment in China [J]. Fujian finance, 2015 (12): 34-36. (In Chinese)

[7] Zhang Daosheng, Xie Qiankun. The third party payment platform for the development of Alipay research [J]. Journal of Jiaozuo University 2016, 3 (1): 69-72. (In Chinese)

[8] Liu Junjian. Analysis of the current situation and the development of third party mobile payment [J]. Science innovation guide, 2016 (24): 8990. (In Chinese)

[9] Zheng Chengde, Liu Xiu, Yang Xue. Studies on the Impact of Perceived Value and Personal Traits on the Consumer's Intention to Purchase of Mobile Shopping [J]. Chinese Journal of Management, 2012 (10): 34-48.

[10] Zhang Huaqiang, Wu Daoyi, Qi Hui etc. Problems and Suggestions on the Development of Mobile Payment in China [J]. Financial Practice, 2013 (3): 86-88. (In Chinese)

[11] Wan Yuanwei. A study of perceived interest, perceived risk and purchase cost on the purchase intention of Internet consumers [D]. South China University of Technology master's degree thesis, 2011.13-27. (In Chinese)

[12] Peng Shuai. Research on the influence factors of customer online purchases intention based on consumption cost theory [D]. South China University of Technology master's degree thesis, 2011.40-63. (In Chinese) 